\title{
Relaciones económicas entre América Latina y Estados Unidos: implicaciones y perspectivas políticas $^{1}$
}

\begin{abstract}
Anfal Pinto Santa Gruz es Profesor de la Escuela. de Economia de la Universidad de Chile y de escolatina y Fundador y ex Director de la Revista Panorama Económico. Entre sus libros figuran Chile, Un Caso de Desarrollo Frustrado; Distribución del Ingreso en América Latina y Tres Ensayos sobre Chile y América Latina. Autor de numerosos artículos, es Director de la División de Desarrollo Económico de la CEPAL.
\end{abstract}

Este trabajo tiene ambiciones muy limitadas. Se propone entregar algún material para discusiones antes que proposiciones o hipótesis enfáticas sobre los temas envueltos. Por otro lado, existe cierto grado inevitable de "inhibiciones institucionales" en el abordamiento del tema, a pesar del carácter personal de la contribución.

En su primera parte, pretendemos pasar revista a los cambios o evolución de las opiniones que se tienen en América Latina y en Estados Unidos respecto al significado recíproco de sus nexos económicos, para contrastarlos en la segunda parte con antecedentes objetivos sobre esos nexos. Por desgracia, sólo hemos podido cumplir en parte ese propósito ya que no nos ha sido posible recoger y sistematizar la corriente latinoamericana de juicios y reacciones sobre el asunto. Hemos tomado, en consecuencia, como punto de partida, únicamente el mutante punto de vista más o menos oficial de Estados Unidos.

En la tercera parte hemos tratado de analizar, sobre el trasfondo de las secciones precedentes, algunos elementos que nos parecen

* Las opiniones expresadas en este trabajo son de carácter personal y no comprometen a la institución a la cual pertenece el autor.

${ }^{1 T r a b a j o}$ presentado a la Conferencia sobre "Las relaciones politicas entre América Latina y Estados Unidos", organizada por el Instituto de Estudios Peruanos y el Social Science Research Council (Joint Committee of Latin American Studies). 
principales para evaluar las posibilidades de conflicto o distensión en las relaciones de las dos áreas.

\section{I. - EL SIGNIFICADO DE AMÉRIGA LATINA DESDE EL PUNTO DE VISTA DE ESTADOS UNIDOS}

Parece evidente que en los últimos años -y con mayor fuerza en la administración Nixon- se ha producido un cambio sensible en los medios oficiales de Estados Unidos respecto a la importancia o significación de América Latina para ese país.

Después del periodo marcado por la guerra fría y las preocupaciones alrededor de la "seguridad hemisférica"; y disipado el espíritu de Punta del Este y los programas de la Alianza para el Progreso, se ha impuesto una nueva actitud. Unos la llaman "the benign neglect" (descuido benigno) ; otros ponen énfasis en el "low profile" (escaso relieve) del problema latinoamericano.

De todos modos, hace poco todavía quedaban entusiastas, como los miembros del Subcomité de Asuntos Interamericanos de la Gámara de Representantes, que en un informe en que el título era más impresionante que el contenido ${ }^{2}$ señalaban que:

"América Latina ocupa un lugar único en la historia de nuestra nación. Compartimos una cultura común, dos siglos de desarrollo nacional independiente, interdependencia económica y un sentido de lejanía tanto respecto al Este como al Oeste. Estos pueden llegar a ser elementos de nuestra fuerza común, determinantes de nuestro papel en los asuntos mundiales. Porque bien puede ser que las modalidades de cooperación internacional, delineadas y aplicadas en este hemisferio, proveyeran un dia un ejemplo a otras regiones y llegaran a ser fundamentos de la paz y la seguridad mundiales".

La. tónica ahora dominante se aparta en grado sustancial de ese enfoque. Conviene recoger algunas opiniones representativas.

Lawrence Harrison, por ejemplo, en un artículo con el sugerente título "Despertando del sueño panamericano"3, señala que:

"La visión de dos grandes continentes, unidos por valores y aspiraciones liberales comunes así como por la geografía, que

I"New directions for the 1970's: towards a strategy of inter-american development", U.S. Government Printing Office, 1969.

${ }^{3}$ Revista Foreign Policy, Ne 5, invierno 1971-72. 
marchan mano con mano hacia un futuro mejor para todos, ha sido distorsionada hasta tornarla ixreconocible por los acontecimientos de los últimos años."

Y rubricando su posición, Harrison agrega que:

"Las diferencias entre América del Norte y América Latina son enormes y cubren virtualmente todos los aspectos de la vida humana. Van mús al fondo que la geografía y el lenguaje. Los norteamericanos y los latinoamericanos tienen diferentes conceptos del individuo, de la sociedad y de las relaciones entre ambos; de la justicia y de la ley; de la vida y la muerte; del gobierno; de la familia; de relaciones entre los sexos; de la organización; del tiempo; de la empresa; de la religión; de la moralidad. Estas diferencias han contribuido a la evolución de sociedades que son más diferentes entre sí que lo que apreciaban nuestros "policy-makers" del pasado. En el hecho, puede argumentarse que hay algunas sociedades asiáticas (Japón es un candidato obvio) que tienen más en común con las sociedades de América del Norte que lo que tiene la mayoría de las sociedades de América Latina."

Entre estas apreciaciones casi antagónicas puede ser útil recordar algunos juicios más realistas y que examinan el problema desde otros ángulos.

Vale la pena recordar entre ellos el expresado por Sidney Weintraub, Secretario ayudante del organismo oficial International Finance and Development:

"Es importante tener presente que nosotros, los Estados Unidos, somos el más importante factor externo, político y econó mico, en la vida de los países latinoamericanos. Cuando los latinoamericanos se pusieron de acuerdo para alcanzar el llamado Consenso de Viña del Max, lo hicieron para demandar varios objetivos económicos, sociales y tecnológicos, principalmente de los Estados Unidos. El reverso del asunto también merece mención: que para la mayoría de nosotros en los Estados Unidos, América Latina no es el factor externo más importante en nuestras vidas. Hay un desequilibrio y este hecho, en si mismo, determina una falta de proporcionalidad en nuestras relaciones. Ello afecta todo diálogo entre nosotros y los países latinoamericanos no importa cuán libre y franco tratemos de hacerlo."

"U.S. policy toward a changing Latin American", Boletín del Departamento de Estado, abril 26, 1971. 
Tras las palabras de Weintraub es fácil descubrir un razonamiento general que se ha atribuido a. Henry Kissinger, el asesor especial del Presidente Nixon. En una reunión del Consejo de Relaciones Exteriores de los Estados Unidos ${ }^{5}$, el señor John N. Plank, del Instituto Brookings y la Universidad de Connecticut, dejó bien en claro lo esencial de esa posición:

-“... estoy completamente convencido de que una excesiva preocupación por la seguridad por parte de Estados Unidos ha dañado seriamente las relaciones Estados Unidos-América Latina, llevando al estado actual de nuestras relaciones: insatisfactorio, frustrante, lastimero".

- "Ha sido públicamente registrado que el doctor Kissinger declara que el mundo actual es militarmente bipolar y políticamente multipolar. Greo que piensa que los desafíos estratégicos más serios para los Estados Unidos provienen, directa o indirectamente, de la Unión Soviética y no de un pais latinoamericano. Pienso que ha descontado la significación del abandono ideológico en América Latina del "american way" y que ha persuadido al Presidente de que no se debe permitir que la protección de los intereses privados de Estados Unidos en América Latina asuma una abrumadora prioridad"...

- "América Latina no es, en el análisis final, de una importancia de vida o muerte para los Estados Unidos, ya sea estratégica, política, económica o ideológicamente. América Latina puede valer una misa pero no vale una dedicación masiva de recursos económicos, energía política o atención militar. Por sí misma, América Latina no puede ir a ninguna parte, -es un lugar "estratégicamente solitario"; y si comienza a ir a alguna parte bajo las directivas de alguna otra gran potencia (la URSS), entonces Estados Unidos tratará con esa otra gran potencia, no con América Latina."

Los cambios registrados no impiden que continúe habiendo sectores importantes que sostienen la trascendencia recíproca de los nexos interamericanos. David Bronheim los identifica desde un ángulo original ${ }^{6}$.

"La versión fue publicada en la revista "Punto Final", No 150,19 de febrero de 1972, Santiago de Chile.

"Relations between the United States and Latin America", en la revista International Affairs, julio 1970. 
"Hay tres grupos que tienden a enfatizar la significación "vital" de América Latina para Estados Unidos - y son extraños "compañeros de lecho". Los marxistas en América Latina, y creo que ellos incluyen un gran porcentaje de la clase intelectual, están resueltos a persistir en la creencia de que la fuerza de Estados Unidos está directamente conectada con la prosecución de la explotación de América Latina... Son acompañados en esa convicción por la comunidad de negocios de Estados Unidos que ticne inversiones en América Latina. Ella subraya constantemente la importancia crucial de América Latina para Estados Unidos, sin duda porque está tratando de mantener interesado al gobierno de Estados Unidos en protegerla a ella y a sus inversiones... Hay otro grupo... un pequeño grupo, muy sentimental y activo... Esta gente tiene una conexión sentimental con América Latina... Muchos de ellos han vivido en América Latina, tienen buenos amigos allá y guardan un arraigado afecto por el área".

Respecto al parecer de las inversiones privadas de Estados Unidos, puede ser de interés reproducir el juicio de Alphonse de Rosso, representante de la Standard Oil en la reunión de Consejo de Relaciones Exteriores de Estados Unidos a que se aludió anteriormente. La versión de sus palabras es la siguiente:

"E1 señor de Rosso dijo que había preparado una discusión sobre un problema de actualidad: la inversión privada de Estados Unidos en América Latina. Algunos creen que los inversionistas tienen demasiada influencia en la formulación de la política de Estados Unidos. Él no está de acuerdo con ese punto de vista, desde luego. La actual inversión norteamericana que llega a los 11 mil millones de dólares, es muy importante para Estados Unidos. Muchos piensan que el desarrollo rápido de América Latina, a lo cual contribuye dicha inversión, es de interés nacional de los propios Estados Unidos. Es sabido que Latinoamerica es una importante fuente de materias primas $y$ por lo tanto la política norteamericana debe tratar de proteger y de promover los intereses de norteamericanos en la región, pero, claro está, en un contexto internacional. Sin embargo, las actuaciones del gobierno norteamericano en el pasado reciente han sido la antítesis de esta idea. Los Estados Unidos han reaccionado pasivamente frente a las acciones tomadas por Perú, Chile y otros países. Nixon dice que no quiere estimular la inversión norteamericana en países donde ella no sea bien recibida. Los Estados Unidos se han mostrado pasivos en las di- 
versas reuniones interamericanas donde se han tratado estos problemas".

El resultado oficial o político-general de los cambios en las actitudes prevalecientes en Estados Uniclos respecto a América Latina se manifiesta en último término en lo que se ha llamado la "doctrina Nixon" sobre la región. Veamos cómo la ha definido un "portavoz representativo - Charles Meyer, Subsecretario de Asuntos Interamericanos. Escogemos algunos párrafos claves de dos intervenciones de ese funcionario:

... "La esencia de la nueva política del Presidente fue acuñada en el término "asociación adulta" ("mature partnership") ... "El mensaje positivo es claro y simple: los Estados Unidos están dedicados a lograr un nuevo equilibrio en nuestras relaciones con América Látina por medio del aflojamiento de nuestra antigua rienda paternalista sobre las otras naciones del hemisferio. El liderazgo tutelar debería ser, y ha sido, reemplazado por una relación equilibrada - que incluye un discreto liderazgo, que respeta los derechos soberanos de nuestros asociados latinoamericanos".

... "La nueva política también anticipa los cambios en América Latina como una fuerza continua y la necesidad de vivir con la diversidad como una de sus derivaciones. Ahora tratamos con los gobiernos tal como ellos son - que es lo que quieren los latinoamericanos".

... "Inherente a la política del Presidente Nixon fue y es el reconocimiento de que deben esperarse diferencias de prioridades, diferencias de intereses, pero que con un espíritu de negociación y no de enfrentamiento, las diferencias pueden manejarse".7

... "Yo debería subrayar cuán radicalmente se ha desplazado el foco de las relaciones interamericanas en la década pasada. Durante este período, los asuntos económicos y sociales se han colocado en el centro del escenario hemisférico. Las preocupaciones en torno al desarrollo dominan ahora el contenido, la dirección y el acento de las políticas internas y externas de América Latina. Una consecuencia de primera importancia para el diseño de la política hemisférica de Estados Unidos es que los países latinoamericanos, en escala creciente, están elaborando

"U.S. policy toward Latin America: where we stand today", Boletin del Departamento de Estado, noviembre 15, 1971. 
sus políticas hacia Estados Unidos y evaluando sus relaciones con nosotros en términos de la incidencia sobre su desarrollo de nuestras intenciones, políticas y acciones". 8

Después de estos planteamientos generales, el Subsecretario se refiere a uno de los aspectos más controvertidos en las relaciones interamericanas: el de las inversiones privadas norteamericanas (el otro problema destacado es el de la frontera marítima). Sobre la materia reiteró argumentos conocidos acerca del papel primordial que se atribuye en la política de Nixon a la participación del capital privado. $\mathrm{Y}$ así parece resumir su criterio básico:

... "Esta convicción no es imperialista ni explotadora. Es un franco reconocimiento de la importancia del instituto empresarial y del "motivo-lucro" en el desarrollo y también una sincera evaluación de la movilidad del capital privado en comparación con los fondos gubernamentales. Sin embargo, mi gobierno reconoce el derecho de un estado soberano a nacionalizar una propiedad extranjera -aunque podamos cuestionar la sabiduría, a corto y largo plazo, de alguna nacionalización. El aspecto vital es el de la compensación- pronta, adecuada y efectiva por cualquier parte o el total de la propiedad que es nacionalizada". ${ }^{9}$

Haciéndose eco de las interrogaciones que abre esa posición, el Subsecretario Meyer plantea en otra parte algunas dudas sobre lo que el problema significa para Estados Unidos. Reproducimos algunas de ellas:

“. ¿Tendremos la sabiduría y la paciencia para mantener nuestro interés de largo plazo en el desarrollo? ¿Podremos evitar la tentación de recurrir a acciones de represalia en el frente de la cooperación cuando diferencias transitorias emergen entre nosotros y nuestros asociados latinoamericanos?

“... Una interrogación persistente y aguda ha sido: ¿Deberíamos mantener nuestros compromisos de cooperar en el desarrollo de países cuyos métodos políticos y hábitos son inconsistentes con preceptos que nosotros valorizamos para nuestro autogobierno? ¿Deberíamos seguir con las tareas de desarrollo a la vez que aceptamos a los gobiernos como son?... ¿Podemos,

\footnotetext{
${ }^{8}$ "Sustaining a meaningful commitment to Latin American Development", Boletín del Departamento de Estado, agosto 30, 1971.

"U.S. policy toward Latin America...", op.cit.
} 
- como yo creo que es esencial- condicionar nuestra colaboración, en el grado de lo posible, a la efectividad con que los gobiernos están dando beneficios a sus pueblos antes que en juicios morales-políticos?10

“... Creo que debemos tratar, en el futuro, estas cuestiones altamente polémicas con un sentido equilibrado y desapasionado, que admite libremente la diversidad y el derecho de otros paises de encontrar su propio destino político". 11

La relación entre estos planteamientos y la realidad está abierta a discusiones y reservas. Greo que varios trabajos de esta Conferencia abordarán el asunto, de modo que no lo haremos aquí. Lo que sí interesa para nuestros propósitos es dejar en evidencia que los cambios en el relacionamiento económico tienen su contrapartida al nivel de las consideraciones políticas, to cual no significa que lo primero sea la causa de lo segundo. Bien se sabe que gravitan en el asunto otras cuestiones de mucho mayor calado. Cabe examinar ahora, sobre la base de lo expuesto, cuál ha sido la evolución de los nexos económicos entre las dos áreas, lo que permitirá verificar la base objetiva de la mutación de actitudes a que se ha hecho referencia.

\section{II. - GARAGTERÍSTICAS, TENDENGIAS Y PARADOJAS EN LAS RELAGIONES ECONÓMIGAS ENTRE AMÉRIGA LATINA Y ESTADOS UNIDOS}

En el curso del pasado decenio y alcanzando también a los últimos años se han ido perfilando algunas tendencias claras en los vínculos económicos entre las dos áreas. Ellas han determinado algunas realidades que son bastante conocidas, pero que esconden hechos que habitualmente se desconsideran y que hasta pueden sorprender.

Para facilidad de la exposición vamos a examinar separadamente las relaciones comerciales y las financieras, para intentar al final una recapitulación global. ${ }^{22}$

${ }^{10 " S u s t a i n i n g ~ a ~ m e a n i n g f u l ~ . . . ", ~ o p . ~ c i t . ~}$

x"Sustaining a meaningful...", op. cit.

${ }^{12}$ Los antecedentes que se expondrán están basados en dos trabajos: A. Pinto y J. Kñakal, "El sistema Centro-Periferia, 20 años después; y J. Kñakal, "Las relaciones económicas entre América Latina y los Estados Unidos en los años sesenta". 
a) La marginalización relativa de América Latina del mercado estadounidense

Si se considera de inicio la corriente de exportaciones, fácil es comprobar la pérdida de posición relativa en el mercado de Estados Unidos que acusan las ventas de la Periferia, en general, y de América Latina, en particular, conciliándose el fenómeno con la expansión absoluta de las mismas (véase el cuadro 1).

Como puede apreciarse (véase indicador 1), las exportaciones de nuestra región crecieron a menor paso que los de la Periferia en

\section{GUADRO 1}

Marginación de amrerica latina del aIERcado de los estados Unidos

\begin{tabular}{|c|c|c|c|c|}
\hline Exportaciones desde/hacia & & $\begin{array}{l}\text { Paises del } \\
\text { Centro total }\end{array}$ & & $\begin{array}{l}\text { tados } \\
\text { nidos }\end{array}$ \\
\hline \multicolumn{5}{|c|}{ 1. Tasa promedia anual (1960-1970) } \\
\hline \multirow{2}{*}{\multicolumn{2}{|c|}{$\begin{array}{l}\text { Países de la Periferia total } \\
\text { América Latina }\end{array}$}} & 7.4 & \multicolumn{2}{|c|}{5.3} \\
\hline & & 5.0 & & $\left(3.2^{\mathrm{a}}\right)$ \\
\hline \multicolumn{5}{|c|}{$\begin{array}{l}\text { 2. Participación en } \% \text { de la impor- } \\
\text { tación total de: }\end{array}$} \\
\hline \multirow[t]{3}{*}{ Países de la Periferia total } & 1960 & 24 & 40 & \\
\hline & 1965 & 21 & 32 & \\
\hline & 1970 & 18 & 25 & \\
\hline \multirow[t]{3}{*}{ América Latina } & 1960 & 8 & 24 & $\left(22^{a}\right)$ \\
\hline & 1965 & 6 & 17 & $\left(17^{\mathrm{a}}\right)$ \\
\hline & 1970 & 5 & 11 & $\left(11^{\mathrm{a}}\right)$ \\
\hline
\end{tabular}

3. Participacion en $\%$ de la expor-

tación total de la Periferia

Periferia total

$\begin{array}{lll}1960 & 72 & 22 \\ 1965 & 72 & 19 \\ 1970 & 74 & 18 \\ 1960 & 79 & 42 \\ 1965 & 72 & 39 \\ 1970 & 74 & 30\end{array}$

FUENTE: Naciones Unidas, Statistical Yearbook y Wonthly Bulletin of Statistics, 1961-1971.

aAmérica Latina, excluyendo a Cuba. 
su conjunto ( $5 \%$ frente a $7 \%$ ) y este retraso se debió fundamentalmente al escaso aumento de sus envíos a los Estados Unidos, que sólo se dilataron a una tasa del $3.2 \%$ anual (excluida Cuba) en el periodo 1960-1970.

A consecuencia de lo anterior, la participación de América Latina en las importaciones totales de Estados Unidos se redujo de 22 a $11 \%$ en los años extremos, señalando una caída mucho más pronunciada que la cuota total de la Periferia, que pasó de un 40 a un $25 \%$ (véase indicador 2).

Ocurrió lo mismo, aunque con menor fuerza, en lo que se refiere a la significación del mercado de Estados Unidos para las exportaciones de América Latina. Mientras el país del norte absorbía poco más del $40 \%$ a inicios del decenio de los años 60 , esa cuota había bajado al $30 \%$ al final del misno. Para Ia Periferia en su conjunto fue menor la declinación de la importancia del mercado de Estados Unidos, ya que entre los plazos señalados la cuota respectiva sólo pasó del 22 al $18 \%$.

Desde otro ángulo y atendiendo a la participación de América Latina en las exportaciones totales de Estados Unidos, se verifica que ella se redujo del $17.4 \%$ al $13.3 \%$ en el plazo $1960-1970$.

Las razones de estos fenómenos son bien conocidas. Por un lado sobresale el hecho del menor dinamismo del intercambio de materias primas por manufacturas, lo que implica, por oposición, que se expandió más el comercio entre los productores-exportadores de bienes industriales que el realizado entre estos últimos y los países productores-exportadores de materias primas $\mathrm{y}$ alimentos ${ }^{13}$. En otras palabras, el factor crucial es la preservación, en lo esencial, de to que el doctor Prebisch llamó "esquema pretérito de división internacional del trabajo" entre Centros y Periferia.

Por otra parte está la circunstancia evidente de que América Latina ha perdido posición relativa vis-à-vis otros segmentos de la $\mathrm{Pe}$ riferia, aunque todos redujeron su participación en el comercio con Estados Unidos. No es posible discutir aquí y. ahora las causas de esa tendencia particular, en la cual no sólo han inflúido las orientaciones de la política de comercio exterior de América Latina, como a veces se subraya. ${ }^{14}$

Por otro lado, el comportamiento de las corrientes de importación y exportación llevó a cambios de gran significación en el balance

${ }^{2: 3} \mathrm{E}$ l comercio entre los países centrales representaba el $64 \%$ de las transacciones mundiales en 1958 y alcanzó al $74 \%$ en 1968. Desde otro ángulo, fue similar al aumento de la proporción de manufacturas en el comercio inter-central. (Véase, "El sistema centro-periferia...", cuadro 2, op. cit.) .

${ }^{14}$ De acuerdo a un estudio reciente de la OEA (CLES, marzo 1969) la marginación relativa de América Latina del mercado estadounidense en los años 60 
comercial. El saldo habitualmente favorable a América Latina (véase el cuadro 4, indicadores I y 2) y que alcanzó a 186 millones de dólares por año en el quinquenio 1961-1965, se transformó en uno negativo en el siguiente y por valor de $25 \mathrm{I}$ millones anuales. La situación se agravó en 1969 y 1970, alcanzando en el último año a 795 millones. Esto, como se verá más adelante, fue decisivo para el desequilibrio acentuado del balance total de pagos en esos años.

En resumen, los antecedentes expuestos, junto con evidenciar con claridad un debilitamiento de los lazos de intercambio, señalan una tendencia al empeoramiento de la posición de América Latina en el tráfico comercial.

\section{Algunos elementos de signo contrario}

La "marginación relativa" de América Latina debe examinarse críticamente a la luz de otros elementos que, si no la contradicen frontalmente, la condicionan en un grado significativo aunque difícil de evaluar con exactitud. Recuérclese, sí, que en esta parte se tocan exclusivamente las cuestiones vinculadas al comercio.

Desde el punto de vista latinoamericano lo primero a tener en cuenta es que, a clespecho de los cambios anotados, Estados Unidos continúa siendo su principal cliente y abastecedor, más lo segundo que lo primero. La situación, claro está, difiere según los países, siendo la excepción un grupo limitado, en el que se encuentran los del Río de la Plata, Chile, Bolivia y Paraguay, aunque para los tres últimos, Estados Unidos seguía constituyendo el primer proveedor hacia fines de los años $60^{15}$. Por otro lado, hay economías como las de México, Colombia, Venezuela, la mayoría de las centroamericanas y Santo Domingo, en las que gravita abrumadoramente el intercambio con Estados Unidos.16

El segundo aspecto a considerar es el de la eventual importancia del mercado estadounidense en el desarrollo de las exportaciones manufactureras de la región. Entre 1960-1969 este rubro creció a una tasa bastante alta, $16.7 \%$ anual, correspondiendo el mayor dinamismo a las ventas dentro de la región y a Europa Occidental, sien-

puede explicarse en una tercera parte por el desplazamiento de la región en beneficio de otros exportadores y en dos terceras partes al cambio en la composición de las importaciones de Estados Unidos en favor de los productos manufacturados.

${ }^{15}$ Sobre la materia y para đetalles más particulares, véase GEPAL, "Tendencias y estructuras de las economías latinoamericanas", Estudio Económico, 1970.

${ }^{10}$ México, por ejemplo, hacia 1968, realizaba alrededor del $55 \%$ de su intercambio con Estados Unidos. Véase "Tendencias y estructuras...", op. cit. 
do algo menor el de las efectuadas a Estados Unidos, $14 \%$ de incremento anual (véase el cuadro 2). Si se toma el último año registrado, 1969, podrá comprobarse que el país del norte absorbió un $30 \%$ de las exportaciones de manufacturas, por valor de 328 millones de dólares y sobrepasando con holgura la representación de los demás países o grupos centrales.

Por otra parte, cabe reiterar la significación actual y potencial de Estados Unidos en relación a algunos items que se exportan casi exclusivamente a ese mercado. Tal es el caso de las ventas regionales de hilados e hilos de algodón, barras y varillas, tuberías de hierro, máquinas de calcular, máquinas y aparatos eléctricos no especificados y otros menores.

Como se comprende, las perspectivas futuras de este tráfico dependen en alto grado de la política de las empresas internacionales de los Estados Unidos arraigadas en la región ${ }^{17}$. Volveremos sobre este aspecto en la parte final, pero dejamos ya sentado que esas

\section{GUADRO 2}

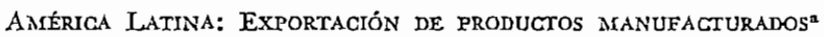
SEGÚN DESTINO

\begin{tabular}{|c|c|c|c|c|c|}
\hline \multirow{3}{*}{ Area de destino } & \multicolumn{2}{|c|}{$\begin{array}{l}\text { Millones de } \\
\text { dólares }\end{array}$} & \multirow{2}{*}{$\begin{array}{c}\text { Tasa } \\
\text { promedia } \\
\text { anual en } \% \\
1969\end{array}$} & \multicolumn{2}{|c|}{$\begin{array}{l}\text { Porcentaje de } \\
\text { participación }\end{array}$} \\
\hline & 1960 & 1969 & & 1960 & 1969 \\
\hline & & & 1960 & & \\
\hline Exportación total & 269 & 1.080 & 16.7 & 100 & 100 \\
\hline Países del Centro & 197 & 536 & 11.8 & 73 & 50 \\
\hline Estados Unidos & - & 328 & $14.1^{b}$ & - & 30 \\
\hline Europa Occidental & - & 177 & $22.2^{\mathrm{b}}$ & - & 16 \\
\hline América Latina & 58 & 500 & 27.5 & 22 & 46 \\
\hline
\end{tabular}

Fuente: Monthly Bulletin of Statistics, marzo y mayo de 1967 , junio de 1971 y GEPAL: América Latina y la Tercera UNCTAD (Documento E/CN.12) L.74, enero de 1972, p. 82).

aSecciones 5-8, excluido capítulo 68 según la clasificación CUCr.

b1961-1969.

${ }^{17}$ Entre 1957 y 1966, las exportaciones manufacturadas de filiales norteamericanas en la región crecieron de 83 a 688 millones de dólares. De estas últimas, 169 millones se colocaron en Estados Unidos (véase H.K. May, "The effects of the United States and other foreign investment in Latin America", The Council for Latin America, enero, 1970). 
perspectivas, según la medida en que se materialicen, involucran un aspecto primordial para la evaluación de la importancia futura del mercado de Estados Unidos para América Latina.

Si se analiza ahora el problema desde la mira del país del norte, también se encuentran elementos importantes para calificar la tendencia a la "marginación" o distanciamiento relativos.

Descle luego, no debe pasarse por alto que las ventas de Estados Unidos, a pesar de su menor representación en los totales, tuvieron un apreciable incremento absoluto, subiendo de unos 3.550 millones de dólares en 1960 a 5.650 millones en 1970 (véase otra vez el cuadro 4, indicador 1), excediendo a las destinadas a África y Asia. Por otro lado, como se verá más adelante, esas exportaciones tienen una representación importante para el balance de pagos de Estados Unidos.

Pero quizás más significativo que las cifras absolutas sean algunos aspectos cualitativos vinculados a la importancia del mercado latinoamericano para ciertas exportaciones del país del norte. En efecto, si tomamos 1968, verificaremos que las compras de productos químicos por parte de América Latina llegaron a 620 millones de dólares, valor muy superior a las respectivas de Canadá, Japón o los países de la AELI y que se comparan favorablemente con las del Mercado Común Europeo, que fueron de 750 millones de dólares. En el mismo año, nuestra región adquirió en Estados Unidos 2.210 millones de dólares en maquinarias y equipo, cifra que sobrepasa a las respectivas del Mercado Común Europeo (1.970 millones), de la AELI (1.260 millones) y del Japón. Por último, recordemos que en lo que concierne a "manufacturas diversas", América Latina sólo fue aventajada como adquirente por Canadá y el MCE.

En relación al mismo punto vale la pena tener en cuenta que las importaciones de América Latina en esos y otros rubros se concentran en un número relativamente pequeño de grandes empresas, que tienen un peso estratégico en la economía de Estados Unidos.

Los antecedentes, si bien dejan en claro la significación del país del norte como proveedor de ingredientes vitales para las economías del área, también evidencian que los mercados del sur tienen una importancia indudable para el funcionamiento del sistema norteamericano.

Se refuerza el aspecto destacado si valorizamos el papel de América Latina como abastecedora de bienes primarios. Como puede verse en el cuadro 3, hacia fines de los años 60 la región proveía a los Estados Unidos del $42 \%$ de sus importaciones totales de 14 productos básicos. El porcentaje fluctuaba entre el 57 y el $80 \%$ para el café, el azúcar y las frutas y legumbres; entre el 31 y el $45 \%$ para el cacao, el mineral de hierro, el cobre, el plomo y el petróleo y de- 
rivados; y entre el 18 y el $26 \%$ de las carnes fiescas y envasadas, los minerales no ferrosos y la lana.

En resumen, pues, un análisis más cualitativo permite vislumbrar que el descenso de las representaciones globales de exportaciones e importaciones va de la mano con la mantención de ciertos nexos básicos o estratégicos para las dos áreas, que no se compadecen, por lo menos, con las hipótesis extremas sobre el distanciamiento o la "prescindibilidad" creciente o irreversible de las mismas.

\section{CUADRO 3}

Estados UnNidos: LMportación de 14 pRoductos básicos de AmÉriga latina

\begin{tabular}{|c|c|c|c|c|c|c|c|}
\hline \multirow[b]{3}{*}{ Grupos } & & \multicolumn{6}{|c|}{ Importaciones procedentes de América Latina } \\
\hline & & \multicolumn{3}{|c|}{$\begin{array}{l}\text { Millones de dólares } \\
\text { (promedio anual) }\end{array}$} & \multicolumn{3}{|c|}{$\begin{array}{c}\text { Porcentaje de la importa- } \\
\text { ción total del producto } \\
\text { respectivo }\end{array}$} \\
\hline & Productos & $1961-65$ & $1966 \cdot 70$ & $\begin{array}{c}\text { Tasa } \\
1966-70 \\
1961-65\end{array}$ & $1961-65$ & $1966-70$ & 1970 \\
\hline 0 y 1 & Alimentos & 1.568 & $1.830^{\mathrm{n}}$ & 3.5 & - & - & - \\
\hline 071 & Café & 828 & 739 & -2.3 & 80 & 69 & 66 \\
\hline 061 & Azúcar & 266 & 385 & 7.7 & 50 & 58 & 57 \\
\hline 051 & Frutas & 130 & 221 & 11.1 & 65 & 69 & 70 \\
\hline 072 & Cacao & 50 & 75 & 8.5 & 32 & 40 & 36 \\
\hline 013 & Carnes envasadas & 41 & 77 & 13.8 & 26 & 26 & 26 \\
\hline 011 & Carnes frescas & 40 & 82 & 15.6 & 14 & 17 & 18 \\
\hline 054 & Legumbres & 32 & 90 & 22.0 & 50 & 75 & 80 \\
\hline 2 y 4 & Materias primas & 514 & $515^{a}$ & 0.1 & - & - & - \\
\hline 281 & Minerales de hierro & 136 & 143 & 1.0 & 38 & 32 & 32 \\
\hline 283 & Minerales no ferrosos & 104 & 94 & -2.1 & 29 & 20 & 21 \\
\hline 262 & $\begin{array}{l}\text { Lana } \\
\text { Además: }\end{array}$ & 61 & 39 & -8.7 & 24 & 21 & 22 \\
\hline 682 & Cobre & 182 & 256 & 7.0 & 58 & 41 & 45 \\
\hline 685 & Plomo & 21 & 30 & 7.2 & 40 & 39 & 36 \\
\hline 3 & Petróleo y derivados & 872 & $988^{a}$ & 2.9 & - & - & - \\
\hline 331 & Petróleo crudo & 547 & 496 & -2.0 & 50 & 38 & 31 \\
\hline \multirow[t]{5}{*}{332} & Derivados & 358 & 475 & 5.8 & 50 & 45 & 43 \\
\hline & Total 14 productos & 2.798 & 3.203 & 2.7 & 50 & 44 & 42 \\
\hline & $\begin{array}{l}\text { Total importaciones } \\
14 \text { productos en } \%\end{array}$ & 3.496 & 4.216 & 3.8 & 20 & 13 & 12 \\
\hline & $\begin{array}{l}\text { De la import. total } \\
\text { De la import. desde }\end{array}$ & 32 & 23 & - & 一 & - & - \\
\hline & América Latina & 80 & 76 & - & - & - & - \\
\hline
\end{tabular}

Fuente: CEPAL, América Latina y la Tercera UNCTAD (Documento E/GN.12/ ?1966-1969.

L.74), enero de 1972, pp. 169 y 171. 
CUADRO 4

América latina: Resumen del balance de pagos con Estados Unidos" (En millones de dólares)

1. Exportación de bienes

2. Importación de bienes

3. Balance comercial (1-2)

4. Saldo de viajes y transporte

5. Servicios de las inversiones
a) Privadas totales
b) Del Gobierno de Estados Unidos

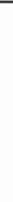

6. Pagos por la inversión de América Latina en Estados Unidos

7. Otros servicios

8. Gastos directos de Estados Unidos en la defensa

9. Balance de servicios $(4+5 c+6+7+8)$

10. Flujos de capital privado

\begin{tabular}{|c|c|c|c|c|}
\hline \multicolumn{2}{|c|}{ Promedios anuales } & \multirow[b]{2}{*}{1969} & \multirow[b]{2}{*}{1970} & \multirow{2}{*}{$\begin{array}{c}\text { Indice } \\
1966-70 \\
1961-65\end{array}$} \\
\hline $1961-65$ & $1966-70$ & & & \\
\hline 3.706 & 4.420 & 4.470 & 4.855 & 119 \\
\hline-3.520 & -4.671 & -4.822 & -5.650 & 133 \\
\hline 186 & -251 & -352 & -795 & - \\
\hline \multirow[t]{2}{*}{30} & -72 & -47 & -76 & - \\
\hline & . & & & \\
\hline-1.165 & -1.638 & -1.753 & -1.693 & 141 \\
\hline-112 & -135 & $-I 49$ & -160 & 123 \\
\hline-1.277 & -1.776 & -1.902 & -1.853 & 139 \\
\hline 75 & 249 & 312 & 332 & 332 \\
\hline 34 & -25 & -18 & -37 & - \\
\hline 77 & 106 & 112 & 118 & 138 \\
\hline$-1.0 \dot{6} \mathrm{I}$ & -1.518 & -1.543 & -1.516 & 14.3 \\
\hline 149 & 399 & 341 & 478 & 267 \\
\hline 289 & 276 & -13 & 558 & 96 \\
\hline 438 & 675 & 338 & 1.036 & 154 \\
\hline 432 & 494 & 540 & 506 & 114 \\
\hline 244 & 272 & 247 & 292 & 111 \\
\hline 120 & 163 & 178 & 189 & 136 \\
\hline 364 & 435 & 425 & 481 & 120 \\
\hline-12 & -27 & -25 & -48 & 225 \\
\hline 1.222 & 1.577 & 1.278 & 1.975 & 129 \\
\hline 347 & -192 & -617 & -336 & - \\
\hline
\end{tabular}

a) Vía inversión directa y compras de valores

b) Vía préstamos

c) Total

I1. Flujos del capital "oficial" de Estados Unidos

12. Transferencias unilaterales
a) Del Gobierno de Es- tados Unidos
b) Privadas
c) Totales

13. Capital de América Latina en Estados Unidos

14. Transferencias $y$ flujos de capital totales $(10 c+11+12 c+13)$

15. Saldo total del balance de pagos $(3+9+14)$

${ }^{a}$ Los datos sobre el balance de pagos entre ambas áreas se presentan en este cuadro siempre desde el punto de vista de América Latina, o sea aquellos con signo positivo ( $(-)$ son ingresos de América Latina (salida para los Estados Unidos) y viceversa los con signo negativo $(-$ ) son salidas de América Latina (ingresos de los Estados Unidos). 


\section{Las relaciones financieras}

Las corrientes financieras entre América Latina y los Estados Unidos acusan tendencias y contradicciones que tienen semejanza con las destacadas en el tráfico comercial $y^{\prime}$ que indudablemente se influyen recíprocamente.

Desde luego, si se comparan los flujos de capital desde el país del norte hacia nuestra región se verificará que este último ha perdido posición relativa a pesar de los incrementos absolutos del mismo (véase el cuadro 4). Así, por ejemplo, la coxriente de capital privado estadounidense pasó de 438 a 675 millones de dólares en promedio anual entre 1961-1965 y 1966-1970; la de capital "oficial", de 432 a 494 millones por año; y las "transferencias unilaterales", de 364 a 435 millones (véanse indicadores 10, 11 y 12 del mismo cuadro). Sin embargo, si tenemos en cuenta la representación de América Latina como destino de la. inversión directa de Estados Unidos, comprobaremos que ella descendió sensiblemente entre los dos decenios pasados. A comienzos de los años 50, esas inversiones componían el $38 \%$ del total, cifra que baja a $16 \%$ hacia fines de los años 60 (1968). Ocurre lo mismo con la Periferia total, aunque con menos fuerza. Son Canadá y el Mercado Común Europeo los que ganan posiciones relativas de mayor entidad. ${ }^{18}$

Conviene mirar más de cerca las evoluciones y significación respectivas de las corrientes oficiales y privadas de capital.

Como puede apreciarse (cuadro 4, indicador 11), las transferencias vía préstamos y créditos oficiales han sido algo menores que las correspondientes al capital privado (indicador 10 del mismo cuadro). Estas últimas aumentaron en $54 \%$ entre los quinquenios considerados, en tanto que las oficiales lo hicieron en menor medida (14\%), acusando una declinación entre 1969 y 1970.'

La situación se torna diferente si también tenemos en cuenta los pagos latinoamericanos por ambos conceptos. Mirada desde el ángulo latinoamericano ella podria resumirse como se hace en el cuadro 5 .

\footnotetext{
${ }^{28}$ Entre 1950 y 1968, las inversiones norteamericanas en los paises desarrollados aumentaron su cuota del 48 al $67 \%$.

${ }^{10}$ Esta se habria acentuado en 1971. Por otro lado, debe tenerse en cuenta que no se considera el capital oficial de Estados Unidos que se canaliza por instituciones como el BIRF o el BWD y tampoco el servicio de estos créditos.
} 
GUADRO 5

AmÉrica Latina: Flujos de los captrales oficiales Y privados DE ESTADOS UNIDOS

1) Capital oficial más transferencias unilaterales

Promedio anuales en millones de dólares

2) Servicio inversiones del gobierno de Estados Unidos

$1961-1965 \quad 1966-1970$

3) Inversiones de capital privado más transferencias unilaterales

$\begin{array}{rr}676 & 766 \\ -112 & -138 \\ 564 & 628\end{array}$

4) Servicio inversiones privadas totales

5) Resultado total

Se percibe claramente que mientras las transacciones del capital privado dejan un saldo anual negativo, ocurre lo contrario con el capital oficial. Sin embargo, el saldo positivo del segundo no alcanza a cubrir el negativo del primero, o sea que no basta para financiar los servicios de la inversión privada. La brecha tendió a ampliarse en la segunda mitad del decenio pasado, subiendo de 43 a I72 millones de dólares anuales.

\section{Las cuentas de la inversión directa}

Por su magnitud no cabe duda de que el servicio de las inversiones directas (no del capital privado total) ha constituido el rubro más importante de las transacciones financieras entre América Latina y Estados Unidos. Es útil, por lo tanto, examinar con más detenimiento los componentes y saldos de las mismas, para lo cual pueden servir las cifras del cuadro 6 .

Como puede apreciarse, los pagos totales se elevaron en $28 \%$ entre los dos quinquenios considerados, siendo su rubro más dinámico el egreso por concepto de patentes y licencias, que creció un $50 \%$, llegando a constituir más de una cuarta parte del total en los años finales considerados. En otras palabras, las retribuciones por "transferencia tecnológica" han ido tomando una creciente importancia. 
Desde el ángulo del ingreso de capitales, la inversión directa resulta el ítem principal, tanto por su magnitud como por su expansión, aventajando con holgura a las compras de valores.

Sin embargo, el aumento del total, nada menos que de $170 \%$ entre los dos quinquenios, no alcanzó a modificar el saldo tradicionalmente negativo de las operaciones, que se mantuvo sobre los 800 millones anuales y que fue decisivo, como se comprende, para conformar el saldo negativo del mismo para las transacciones financieras totales.

Pero hay algo más que tiene ciertamente importancia crucial para el asunto. Es el hecho de que los aumentos aparentes de la inversión directa en la región son financiados en gran medida por las utilidades no distribuidas y otros fondos locales y no por "dinero fresco" proveniente del exterior. Este tipo de recursos representó en algunos lapsos del decenio.(1963-1965) alrededor del $90 \%$ de la inversión directa registrada.

\section{Nexos y contradicciones entre las corrientes financieras $y$ las comerciales}

La estructura y tendencias deficitarias de las transacciones financieras de América Latina con Estados Unidos deben revisarse teniendo a la vista lo señalado antes sobre los nexos comerciales. De ese cotejo se desprenden algunas contradicciones llamativas.

Una de ellas emerge de la disociación entre el crecimiento de los compromisos financieros de nuestra región y su marginación relativa del mercado del país del norte. Entre los dos quinquenios de los años 60 las exportaciones de América Latina con ese destino aumentaron en un $19 \%$, en tanto que los pagos totales por las inversiones norteamericanas en la región lo hicieron en un $39 \%$. En otras palabras, y como señala Jan Kñakal en su trabajo precitado, "América Latina tenía que 'devolver' a los Estados Unidos una parte creciente de sus ingresos procedentes de las exportaciones hacia este país (un 34\% en 1961-1965 y más de un $40 \%$ en la segunda mitad del decenio) para cubrir los servicios de las inversiones estadounidenses en su territorio".

La otra faceta de esa contradicción "comercial-financiera" reside en el hecho ya expuesto de que las importaciones latinoamericanas desde Estados Unidos se elevaron considerablemente más que sus exportaciones a ese país. De este modo, el balance comercial tradicionalmente favorable para nuestra región se tornó negativo en la segunda parte del decenio, con una clara inclinación a un mayor deterioro en los últimos años. En consecuencia, América Latina quedó 


\section{CUADRO $\dot{6}$}

Amt́rica latina: Cuenta de la inyersión Directa de Estados UnNDOS

(En millones de dólares)

\begin{tabular}{|c|c|c|c|c|}
\hline \multicolumn{5}{|c|}{ Promedios anuales } \\
\hline & & & & $1966-70$ \\
\hline $1961-65$ & $1966-70$ & 1969 & 1970 & $1961-65$ \\
\hline
\end{tabular}

Egresos

$\begin{array}{lrrrrr}\text { Patentes y licencias } & -167 & -251 & -272 & -282 & 150 \\ \begin{array}{c}\text { Intereses, dividendos, } \\ \text { utilidades }\end{array} & -811 & -997 & -1.049 & -899 & 123 \\ \quad \text { Total } & -978 & -1.249 & -1.321 & -1.181 & 128\end{array}$

Ingresos netos

\begin{tabular}{|c|c|c|c|c|c|}
\hline Inversión directa & 75 & 301 & 299 & 349 & 401 \\
\hline Compra de valores & 74 & 98 & 52 & 129 & 132 \\
\hline Total & 149 & 399 & 351 & 468 & 270 \\
\hline Saldo neto & -829 & -849 & -970 & -713 & 102 \\
\hline \multicolumn{6}{|c|}{ Saldo de las transacciones } \\
\hline financieras totales & 347 & -192 & -617 & -336 & - \\
\hline
\end{tabular}

Fuente y notas: Véase el cuadro 4.

imposibilitada de solventar los saldos desfavorables de las transacciones financieras con el superávit comercial y por necesidad debió recurrir a mayores endeudamientos o/y baja de reservas para hacer frente a su desequilibrio global.

Significación de las transacciones para las dos áreas

Es obvia la significación para América Latina de las transacciones con Estados Unidos. Aparte de lo ya indicado en el campo del comercio y respecto a la influencia de los nexos financieros sobre el desequilibrio del balance de pagos, hay que tener en cuenta también otros aspectos.

Uno de ellos es la gravitación de las inversiones directas sobre el ritmo $y$, sobre todo, el "estilo" o modalidad de desarrollo de 
América Latina ${ }^{20}$. Otro es la representación del capital oficial de Estados Unidos, que proveía un 80 y un $50 \%$, respectivamente, del financiamiento público externo en el primer y segundo quinquenio de los años 60, sin considerar lo canalizado vía agencias internacionales de crédito. Como se comprende, estos datos globales no revelan la gran concentración de los dos tipos de corrientes en algunos pocos países, sobre todo en Brasil y México, en los últimos años.

Miradas las cosas desde el ángulo de Estados Unidos, parecería a primera vista, que las transacciones financieras y totales tienen reducida importancia. Así es, sin duda, $y^{\prime}$ pese a lo que se sostiene en algunos círculos, si se comparan las cifras expuestas con el producto nacional de Estados Uniclos o sus vínculos con otras regiones desarrolladas.

Sin embargo, se vislumbra una realidad diferente si se examinan algunos aspectos particulares y de valor cualitativo.

Tal es, por ejemplo, la contribución al balance de pagos de Estados Unidos, que involucran los saldos favorables de las relaciones con América Latina. Ella significó un $10 \%$, en promedio, en los años 1961-1965; y un $25 \%$ en el segundo decenio, del saldo positivo del intercambio total de bienes y servicios de Estados Unidos en esos periodos. ${ }^{21}$

En breve, por ese camino, América Latina ha dado un apoyo de envergadura al país del norte en su crisis reciente de balance de pagos. Conviene también tener en cuenta que la magnitud de ese apoyo excede en mucho a lo que representó América Latina en la distribución de la inversión directa norteamericana. En el hecho nuestra región sólo recibió un $5 \%$ y un $10 \%$ de las inversiones en el primer y segundo quinquenio de los años 60 . En otras palabras, mientras nuestra región, en los últimos años del decenio, estaba contribuyendo con más de un tercio del ingreso neto de Estados Unidos procedente del intercambio comercial $\mathrm{y}^{\prime}$ de servicios, sólo estaba recibiendo alrededor de una décima parte de la inversión directa y la cuarta parte de los préstamos del gobierno de Estados Unidos.

\section{Una recapitulación}

Una visión completa de las relaciones comerciales y financieras entre las dos áreas podría llevar a las siguientes conclusiones.

De un lado, es evidente el debilitamiento relativo de los lazos entre América Latina y los Estados Unidos en los dos planos consi-

${ }^{20}$ Véase al respecto, A. Pinto, "El modelo de desarrollo reciente de América Latina", Trimestre Económico, N8 150.

${ }^{2 x} \mathrm{El}$ porcentaje subió a $39 \%$ en 1969 y a $34 \%$ en 1970. 
derados y sin perjuicio de la apreciable expansión absoluta de las transacciones.

Por otra parte, lo anterior va de la mano con el significado "estratégico" que tienen ciertos nexos tanto para nuestra región como para Estados Unidos. Para la primera, el país del norte continúa siendo el principal cliente y abastecedor en lo comercial y la fuente mayor de capitales oficiales y privados. Para Ios Estados Unidos, las economías del sur juegan un papel de importancia como origen de una serie de productos básicos, a la vez que son clientes destacados en lo que se refiere a ciertos bienes industriales. Más aún: las transacciones con América Latina han involucrado un soporte de consideración para el cuadro global de su balance de pagos.

Finalmente, habría que subrayar el sensible y creciente desequilibrio que acusan las relaciones económicas en perjuicio de América Latina. El tiene su origen tanto en los desniveles del comercio (América Latina importa bastante más de Estados Unidos que lo que éste compra en la legión). como en el desbalance de las corrientes financieras, originado en el peso y crecimiento de los compromisos de América Latina que está lejos de compensarse con un flujo proporcional de créditos $y$ capitales norteamericanos. Las tendencias del comercio, en lugar de proveer medios para hacer frente a ese desequilibrio, han tendiclo a acentuarlo en los últimos años al inclinarse la balanza comercial en contra de América Latina.

Corresponde examinar en la siguiente y última parte de este trabajo cuáles son las perspectivas próximo-futuras de estas realidades y barajar algunas ideas sobre sus connotaciones políticas.

III. - LAS PERSPegtivas: elententos de Distensión Y de conflictos

Contra el trasfondo que establecen las dos secciones anteriores intentaremos ahora discutir algunas perspectivas, tal como se ven en el presente y como se pueden imaginar respecto del próximo futuro, digamos hasta el final de los años 70.

Para el efecto parece indispensable colocar el asunto en un contexto más amplio, que considere las opciones y tendencias que se disciernen en el proceso de reajuste de la economía (y la política) mundial. A nuestro juicio, la fisonomía del "nuevo orden" emergente tendrá gran significación para el problema que nos interesa.

El tema fue planteado en un documento reciente de la CEPAC?2 y los aspectos sustanciales son los siguientes:

22Estudio Económico de América Latina, 1970, Vol. I, Primera Parte. 
"Una posibilidad es que tras los reajustes de mecanismos y prácticas se reanude el proceso de "integración horizontal" de las economías desarrolladas de mercado"... "Las oportunidades para continuar $y$ ensanchar aquella "integración horizontal de las economías desarrolladas evidentemente se fortalecerán con el ingreso de nuevos e importantes miembros al Mercado Común Europeo y eventualmente mediante futuras negociaciones entre Estados Unidos, la CEE y Japón. Pero hay más. Sucesos relativamente próximos han mostrado posibilidades amplias, aunque difíciles todavía de cuantificar, de extender o incorporar al proceso anterior a las principales naciones socialistas o sus agrupaciones regionales. En este respecto deben tenerse en cuenta no sólo los acuerdos gestionados entre economías de Europa occidental, Japón y Estados Unidos con la Unión Soviética sino también las oportunidades que puede abrir el nuevo cuadro de relaciones con China"...

"Otras corrientes son más pesimistas sobre la posibilidad de abordar y prolongar esa "integración horizontal" de las grandes economías industriales... ese punto de vista se inclina por la tesis general de que al cerrarse esta etapa es más probable que se acentúe la reconstitución aunque sea sobre bases diferentes, de agrupaciones o bloques "verticales", tendencia, por lo demás, que ya venía insinuándose". ${ }^{23}$

¿Qué significación e implicaciones tiene esa alternativa para América Latina?

Desde un ángulo general, -y que envuelve a toda la Periferia-, parece evidente que la primera opción redundaría en nuevos impulsos para las transacciones intercentros, que ahora incluirían plenamente a las economias socialistas. Por otro lado, es igualmente claro que si bien y derivadamente podría activar las exportaciones de la Periferia hacia Ios centros, también importaría acentuar el fenómeno de la marginación relativa de los países subdesarrollados $y$, por ende, el del desarrollo desigual y desequilibrado de las dos grandes esferas, en la medida, claro está, que se mantenga el esquema "pretérito" de división internacional del trabajo. ${ }^{24}$

nasobre este aspecto, véase T. Greigh. "Toward a world of trade bloks", National Planning Association, "U.S. Foreign Policy on the 70's", november 1971, Washington.

"Nótese que el desenvolvimiento de la "integración horizontal" a nuevas áreas, v.g., las economías socialistas, en especial la URSS, implica el acceso a una gran "despensa" de productos primarios, que en muchos casos (cobre, petróleo, etc.) son fuentes alternativas de abastecimiento respecto a América Latina. 
Un cambio de rumbo en el sentido de las "integraciones verticales" tendría otras consecuencias. Quizás debilitaría relativamente el proceso de asociación de los centros y fortalecería, en cambio, los nexos entre los países-ejes o sectores de cada grupo y las economías afiliadas, con el consecuente y casi inevitable agravamiento de la subordinación de las segundas.

Replanteada la cuestión en términos del problema que nos preocupa, sería razonable deducir que la primera opción envolvería menores posibilidades de conflictos, por la simple razón de que continuarían debilitándose los lazos económicos generales, todavía muy significativos, como hemos visto, que relacionan a América Latina con los Estados Unidos. A la inversa, la segunda tendencia podría conjugar un grado mayor de intercambio y nexos financieros con posibilidades más amplias de tensiones y' querellas.

Es legítimo objetar que el análisis tiene algo del dicho "palos porque bogas y palos porque no bogas", pero conviene tener en cuenta que esa realidad corresponde fielmente a las contradicciones involucradas en cada una de esas opciones. Por eso mismo es comprensible que los países de la Periferia, con poco éxito y a veces con insuficiente vigor, pugnen por otro tipo de ordenamiento mundial. Sus trazos gruesos están expuestos en el documento de la CEPAL antes mencionado y del modo siguiente:

"De cualquier modo, los intereses de la periferia estarian mejor cautelados si la nueva ordenación implicara un progreso definido hacia una verdadera "integración internacional", que ni alejara a las economías en clesarrollo de las influencias dinámicas del progreso material, científico y tecnológico de las naciones avanzadas, ni significara acentuar las nuevas modalidades de dependencia que se han ido perfilando en el esquema que hoy hace crisis.

Esta perspectiva no tendría por qué oponerse a las agrupaciones de países que han cristalizado en estos años ni podría ignorar la desigualdad manifiesta de las partes que componen el conjunto mundial, $y$, concretamente, las diferencias de posiciones objetivas de las economías industrializadas y las en desarrollo, que exigen tratamientos preferenciales para las naciones de la periferia dentro de un arreglo global. En suma: esa integración internacional supone necesariamente regímenes o modalidades que mejoren sustancialmente la posición de las últimas en el contexto mundial.

Por otro lado, es también evidente que un nuevo arreglo internacional en alto grado de la continuación con mucha mayor energía y éxito de los procesos de integración regional o subre- 
gional de las economías de los países en desarrollo. Con el tiempo se apreciará con mayor claridad que esos avances son vitales. tanto para utilizar más plenamente y en mejor forma el potencial de desarrollo de las naciones de la periferia como para elevar su poder de negociación frente a las economías y grupos industrializados.

La cooperación y complementación creciente del conjunto o parte de los países de la periferia tiene un sentido muy particular y positivo. Ese movimiento, lejos de implicar un intento de separarse de las economías desarrolladas o de dividir el sistema económico mundial, significa un instrumento para integrar efectivamente y en condiciones justas y propicias a los países de là periferia en esa globalidad, colocándose así sobre bases más sólidas. y expansivas sus nexos con las economías industrializadas".

Las nuevas agencias de relacionamiento: las empresas internacionales

La segunda cuestión a examinar en esta parte tiene que ver con el papel creciente y a la larga dominante de las empresas intermacionales como agencia o mecanismo de relacionamiento de las economias de la Periferia (en especial las semi-industrializadas y de mayor porte) con las capitalistas desarrolladas. Esto subentiende otra hipótesis de sentido contrario: que se reducirá la significación relativa de las inversiones "tradicionales" (por ejemplo, en el sector exportador-primario: cobre, petróleo, etc.) y de las correspondientes a capitales oficiales o institucionales. Naturalmente, estas presunciones no son válidas para el caso de experiencias socialistas "totales".

La interrogación que plantea el presupuesto es la siguiente: esos nuevos mecanismos de relación ¿serán más o menos conflictivos que los antiguos?

Sobra decir que no caben contestaciones enfáticas o de valor universal en la materia. Sin embargo, quizás pueden hacerse algunas especulaciones razonables.

Aunque de ningún modo se pasan por alto las reservas y críticas de diverso orden que ha merecido la gestión de las empresas internacionales ${ }^{25}$, desde el ángulo del asunto discutido es útil tener presente varios elementos.

Uno primero y "operacional" deriva del propio carácter "internacional" de esas entidades, que no niega la base y arraigo "nacional"

${ }^{26}$ Véase, por ejemplo, en lo que respecta al autor, el trabajo sobre "CentroPeriferia, 20 años después", versión final, pág. 27 y siguientes. 
de las casas matrices, pero que indudablemente les confiere una flexibilidad mucho mayor que la empresa extranjera tradicional... Existen numerosos ejemplos demostrativos de esa condición. Entre ellos están sus acuerdos con economías socialistas europeas y otros que han negociado con países "socializantes" o "en transición al sociạlismo".

Un segundo aspecto, más sustancial, sobre todo en el caso de varias naciones latinoamericanas, es que esas empresas están abiertas a una competencia más o menos activa de sus congéneres. En otras palabras, no es posible olvidar que las de origen norteamericano, por ejemplo $-y$ a la inversa de lo que ocurria con las "tradicionales"-, conviven y rivalizan con otras de variados orígenes: italianas, japonesas, alemanas, francesas, holandesas, etc.

Esta circunstancia acrecienta, sin duda, el radio de maniobra o de negociación de las economías donde se asientan y constituye un factor objetivo y potencial de envergadura. Esta realidad se robustece por el hecho de que su actividad se encuentra relativamente "integrada" en el sistema productivo interno y subordinada en diversos grados a las clirectrices de la política económica general y particular.

Podrá objetarse, claro está, que en muchos casos es tal el poder de esas empresas que ellas pueden supeditar las decisiones a sus intereses. Aún así, no podría negarse que su "colocación" general y el alcance eventual de las políticas nacionales difieren sensiblemente de la realidad planteada en los anteriores aspectos por la. empresa "tradicional" primario-exportadora.

Lo dicho, entiéndase bien, no involucra una suposición de "armonía de intereses" o ausencia de fricciones y conflictos. Nada de eso. Apenas pretende sostener que los grados de contradicción probablemente son menores que en el cuadro del pasado y, a la inversa, que son mayores las oportunidades potenciales de negociación y control para los países involucrados.

La verdad es que las empresas internacionales, sobre todo las organizadas como conglomerados, constituyen un "fact of life" del mundo actual, seguramente otra fase de la "etapa superior del capitalismo". Como anotó el Secretario de la Comisión Económica de Europa, Janos Stanornik, "Las empresas multinacionales han dejado de ser una cuestión respecto a la cual uno puede estar a favor o en contra. Estas compañías producen anualmente 300 mil millones de dólares, algo similar al valor del comercio mundial. Esto es un hecho. Gran parte de la fuerza subyacente aquí en Europa está dada por esas empresas". 26

${ }^{26} \mathrm{En}$ "The delegates world bulletin", agosto 14, 1972. 
Proyecciones y realidad politica de los nexos

El último aspecto a considerar en este examen sumario de los elementos de distensión y conflicto en las relaciones de América Latina con los Estados Unidos es el que tiene que ver con las implicaciones políticas de las mismas y con el cuadro general de la "política de poder" o "power politics" internacional.

Tratamos de examinar el asunto hace algún tiempo en otro trabajo y creemos que todavía es útil volver sobre los principales puntos allí planteados. 27

El primer hecho considerado es que "en ninguna de las regiones del mundo donde se proyecta la política norteamericana parece tener una gravitación comparable a la influencia de sus negocios privados. En tanto que estos últimos no son variable principal o decisiva en áreas donde la inversión no es considerable (por ejemplo Asia) o donde las consideraciones político-generales son primordiales (por ejemplo, Europa occidental), ocurre que en América Latina ellos tienen un peso enorme, que a menudo sobrepasa la evaluación política de los Estados Unidos como un todo o como nación... Mucho depende en estas materias de la fisonomía de la coyuntura. Si el país del norte está en jaque en un momento dado, -digamos Segunda Guerra Mundial o primera fase de la revolución cubana-, el criterio "macro-político" o "nacional" adquiere más fuerza relativa. A la inversa, en circunstancias más normales, la "micro-visión privada" tiende a predominar".

Con respecto a esta hipótesis habría que traer a colación dos aspectos ya abordados y que hacen presumir para el próximo futuro, -y las demás cosas siendo iguales-, una mayor gravitación relativa de la "macro-visión" por parte de Estados Unidos. Uno es el fortalecimiento de la "coexistencia pacífica" con el mundo socialista, que reduce la prioridad del elemento "seguridad" y también templa la disposición a solidarizar con los intereses privados.

El otro factor sería el cambio en la naturaleza o composición de esos intereses. En otras palabras, podría argüirse que el nuevo tipo de empresas, a la vez, es menos "conflictivo" que los negocios tradicionales y por su propio carácter "transnacional" tiene menos posibilidad de presión o de identificar sus intereses con el global de Estados Unidos.

La segunda cuestión se vincula al revestimiento o implicación

${ }^{27}$ Véase "La crisis latinoamericana en su marco externo", Revista Desarrollo Económico, julio-diciembre 1966, Buenos Aires. También en "La dominación en América Latina", Colección América, Problemas, Lima, 1967. 
político-ideológico de cualquier conflicto eventual entre los negocios extranjeros y el país sede. Sólo para fines de análisis puede imaginarse al respecto una alternativa extrema: que el conflicto no envuelva $o$ no derive en un enfrentamiento político-ideológico con el país donde está radicada la matriz del negocio extranjero; o que ese ingrediente, por designio o por el desarroillo o carácter de la oposición, llegue a ser fundamental.

En el trabajo antes citado la cuestión se exponía de la siguiente manera:

“... al igual que en otras áreas o países, parece de toda conveniencia la disociación del proceso de cambios internos de las afiliaciones de la guerra fría. Esto es, frente a la internacionalización de hecho de ese fenómeno, lo que debe perseguirse es su internalización.

Sobre decir que tal afirmación apenas tiene significado en un sentido relativo. Aparte de las circunstancias diferentes que rigen en América Latina frente a otros lugares (por ejemplo, Egipto o Argelia), en que transformaciones de carácter revolucionario no exigieron un salto de trinchera en la querella de las superpotencias, está el hecho meridiano de que, en todo caso, alguna vinculación existe entre las orientaciones domésticas $y^{\prime}$ la política exterior. El problema estriba en delinear estos últimos nexos, que serán distintos en cada país y que se modificarán según varien los cuadros interior y externo.

Para seguir el análisis supongamos que en un país se crean condiciones domésticas propicias para mutaciones sustantivas que tendrán sin duda, alguna proyección sobre la política exterior. La cuestión en debate es si esa rectificación involucra o lleva necesariamente al rompimiento con la superpotencia actualmente hegemónica y el plegamiento a las filas opuestas.

Para examinar las alternativas existentes es preciso rebajar el nivel de abstracción e introducir algunos elementos más específicos.

En principio hay que distinguir algunos de carácter económico.

En ciertos países - no obligadamente en todos - una política de transformaciones medulares puede requerir decisiones que afecten intereses extranjeros que, para simplificar, identificaremos con los norteamericanos. En estas circunstancias, como ya vimos, los afectados tenderán a fundir su problema particular con el de los Estados Unidos como ente nacional. Que lo consignan o no dependerá de varios factores, que pueden obrar separadamente o de consuno.

En primer lugar, de la envergadura de esos intereses y de su 
poder de presión en el país del norte. En segundo término, de la significación de las inversiones para el abastecimiento actual o eventual de los Estados Unidos. Sobra resaltar que la expropiación de una planta de refrescantes o de una fábrica textil no tendrá la misma repercusión que un intento de nacionalizar los yacimientos de petróleo de Venezuela o los de cobre de Chile. Por último, de los expedientes aplicados para transferir los activos extranjeros al clominio nacional, esto es, si es una confiscación, alguna forma de expropiación o una mera adquisición.

Veamos ahora algunas variables políticas.

Aqui podríamos reducir las posibilidades a dos grandes familias. En una, la que podría calificarse de nacional-desarrollista, la conducta fiente o contra los enclaves foráneos estaría dictada primordialmente por un juicio respecto a su importancia para las tareas del desenvolvimiento económico y social del país. En la segunda, tales pasos se encontrarian determinados principalmente por consideraciones ideológicas, esto es, por la lógica de la acción antimperialista $y^{\prime}$ por el objetivo final de hostigar o perjudicar a la potencia hegemónica.

Evidentemente, es poco menos que imposible encontrar esos dos tipos o alternativas puras; sin embargo, la mayor o menorproporción de una u otra motivación tiene una gravitación decisiva para el análisis."

Seria muy arriesgado aventurarse a formular una hipótesis sobre la fisonomía eventual que pueda adoptar esta cuestión en el futuro próximo. Algunos elementos antes destacados parecerían indicar que las condiciones presentes serían más propicias para separar los dos planos del asunto, esto es, un conflicto a nivel concreto o económico y el que pueda proyectarse en la dimensión político-ideológica. Pero no hay duda que esa hipótesis sería fácilmente criticable como ingenuidad o limitación "economicista".

Más aún, si se introduce el problema general de las "políticas de poder" o "power politics", podría sostenerse que las condiciones que avalan una apreciación relativamente optimista en la materia estarían expuestas a ser sobrepasadas por consideraciones de tipo estratégico-militar mucho más poderosas y pertinentes. Dejamos constancia de este hecho aunque no estamos en situación de discutirlo adecuadamente. 28

${ }^{28} \mathrm{Un}$ indicio del problema puede encontrarse en el análisis siguiente: "A pesar de que la importancia estratégica que se atribuye al control sobre vastos territorios ha considerablemente disminuido, en función de la capacidad nuclear expresada por los cohetes de largo alcance, sigue siendo, tanto para Estados Unidos como para la URSS, un principio básico el directo control sobre sus respectivas áreas. El 
Sea como sea, no caben conclusiones rotundas sobre el problema, aunque nos parece que cualquier hipótesis razonable deberá tomar en cuenta los elementos que hemos tratado de destacar en esta parte.

hecho mismo de que "el equilibrio del terror" limita enormemente la posibilidad del uso de armas nucleares, justifica la necesidad del mantenimiento de fuerzas convencionales bien equipadas en las zonas más amplias posibles. El mantenimiento de bases y de fuerzas militares de las superpotencias en territorios extranjeros demuestra notablemente este hecho. Por otro lado, el mantenimiento de tropas en los países adyacentes o el control sobre los ejércitos de estos países son una garantía indispensable para la continuación de regímenes de gobierno leales a la superpotencia correspondiente. Una politica que fue formulada hace muchos años atrás tomando en cuenta.consideraciones geopolíticas, está basada ahora -en el caso de la Unión Sovietica y los Estados Únidos- en la necesidad de unirse con un bloque de "satélites" o países periféricos o aliados, quienes vienen a acentuar la condición de liderazgo y el status central de los superpoderes". "Los Estados Unidos y la URSS en América Latina y en Europa Oriental", por Edy Kaufman, Revista Aportes, No 24, abril de 1972. 